\title{
n-Heptane hydroconversion over sulfated-zirconia-supported molybdenum carbide catalysts
}

\author{
F. F. Oloye ${ }^{1} \cdot$ A. J. McCue ${ }^{1}$ J. A. Anderson ${ }^{1}$
}

Received: 25 April 2016/Accepted: 3 October 2016/Published online: 19 October 2016

(c) The Author(s) 2016. This article is published with open access at Springerlink.com

\begin{abstract}
Molybdenum carbide on sulfated zirconia was prepared by impregnation of $\mathrm{MoO}_{3}$ on sulfated zirconia to give a loading of $5 \mathrm{wt} \%$ followed by carburisation at $923 \mathrm{~K}$ in a mixture of $\mathrm{CH}_{4} / \mathrm{H}_{2}$ (4:1). The resulting catalyst was characterised by $\mathrm{N}_{2}$ adsorption-desorption, $\mathrm{CO}$ chemisorption, FTIR of pyridine adsorption, XRD, TPR, TGA, Raman and SEM-EDX. This combination of characterisation studies suggests formation of a well-dispersed $\mathrm{Mo}_{2} \mathrm{C}$ phase over tetragonal zirconia. When employed in the hydroconversion of $\mathrm{n}$-heptane, high temperature and low space velocity lead to substantial cracking. However, under some conditions, an increase in the research octane number (RON) from 0 (n-heptane) to ca. 50 was attained. Between 723 and $873 \mathrm{~K}$, n-heptane is mainly cracked to iso-pentane and ethane. The product distribution as a function of conversion suggests that the reaction did not simply follow a consecutive reaction pathway, but that other parallel routes were involved.
\end{abstract}

Keywords Molybdenum carbide $\cdot$ Sulfated zirconia $\cdot \mathrm{n}$ heptane $\cdot$ Cracking $\cdot$ Isomerisation

\section{Introduction}

Octane number is a measure of resistance of an engine to auto-ignition or premature detonation when exposed to heat and pressure in the combustion chamber of an

J. A. Anderson

j.anderson@abdn.ac.uk

1 Surface Chemistry and Catalysis, Materials and Chemical Engineering Group, School of Engineering, University of Aberdeen, Aberdeen AB24 3UE, UK internal-combustion engine [1]. Octane number can be improved by conversion of straight-chain hydrocarbons to iso-alkanes and this has classically been achieved through reforming. However, reforming also enhances aromatic yield via dehydrocyclisation/aromatisation which creates issues for refineries given that legislation now limits the quantity of aromatics, in particular, benzene which are allowable in a fuel [2,3]. Hydroisomerisation is a catalytic process for conversion of linear alkanes to branched alkanes in the presence of hydrogen, at low temperature, and offers an alternative to reforming since it does not produce aromatics. Hydroisomerisation catalysts involve two different types of active sites: metal sites for hydrogenation and dehydrogenation and an acidic support for rearrangement of the hydrocarbon structure. The hydroisomerisation of C4-C6 hydrocarbon is performed on industrial scale, but there is no established catalyst for heptane isomerisation [4, 5]. Solid acid catalysts (such as platinum on chlorided alumina) that operate at low temperature $(<423 \mathrm{~K})$ are the current preferred catalysts used in refineries, because they give high activity at low temperature, which favours isomer yield, given the exothermicity of the isomerisation reaction $[4,6,7]$. The problem of corrosion and waste disposal are the major challenges with this type of catalysts. Another example of catalyst that has been widely reported to be active at low temperature is a catalyst based on sulfated zirconia [8-13]. However, this type of catalyst appears susceptible to deactivation which appears to originate from high levels of carbonaceous deposits derived from cracking of higher alkanes, poor resistance to poisons such as water, and sulfate loss at high temperature [6, 14, 15].

Molybdenum-based catalysts are employed in many reactions [16] in part due to the numerous different molecular structures and oxidation states, which supported molybdenum species can take. Mo structures and oxidation 
states are determined by preparation parameters such as loading, preparation method, calcination temperature, reduction temperature and reaction temperature [17]. One area of interest is in their ability to form carbides through the insertion of carbon into the lattices of Mo. The carbon donates its valence electron into the outer $\mathrm{d}$ band of Mo resulting in the appearance of a narrower metallic type band with a density of states at the Fermi level similar to that of a noble metal [18, 19]. As a consequence, this permits their use in a wide variety of reactions including: dehydrogenation [20, 21], hydrogenation [16], methane dehydroaromatisation [22], methane reforming [23, 24], methane capturing [25], methanol oxidation [26], alcohol synthesis [27, 28], alkyne metathesis [29], CO hydrogenation [30], water-gas shift [31, 32], hydroisomerisation [6, 33-35] and hydrotreating [36].

There are some reports that molybdenum oxide/carbide/ oxy-carbide may be active for isomerisation reactions [37, 38]. Matsuda and co-workers [5], in a study involving $\mathrm{H}_{2}$-reduced $\mathrm{Pt} / \mathrm{MoO}_{3}-\mathrm{SiO}_{2}$ for heptane isomerisation, showed that activity of the catalyst increased with higher $\mathrm{MoO}_{3}$ loadings, while at low $\mathrm{MoO}_{3}$ loading, no activity for heptane isomerisation was apparent [5]. However, the activity of Mo at low surface concentration was reported to be higher on zirconia compared to alumina or silica [17]. n-Alkane hydroconversion studies at $723 \mathrm{~K}$ over high loaded molybdenum carbide supported on sulfated zirconia lead to iso-heptane selectivity of $\geq 85 \%$ at a conversion above $50 \%$ [6]. The catalyst was also found to be stable for $6 \mathrm{~h}$ reaction on stream. Addition of noble metal onto $\mathrm{MoO}_{3}$ was reported to be effective in enhancing heptane isomerisation activity [5, 39]. However, in the case of $\mathrm{Rh} / \mathrm{MoO}_{3} / \mathrm{ZrO}_{2}$, the addition of the noble metal facilitated reduction/carburisation, but reaction over the activated catalyst was dominated by $\mathrm{Rh}$-based hydrogenolysis activity [34]. Hence, avoiding expensive noble metal could be advantageous. The aim of this work is to gain an understanding of the reaction processes related to upgrading heptane using low loading of $\mathrm{Mo}_{2} \mathrm{C}$ on sulfated zirconia and to study the role of the individual components in determining the formation of specific products.

\section{Experimental}

\section{Preparation of materials}

The sulfated zirconia was prepared by calcination of sulfated zirconium hydroxide (MEI chemicals) at $823 \mathrm{~K}$ for $3 \mathrm{~h}$ and is denoted as 'SZ'. A solution of ammonium heptamolybdate tetrahydrate $(0.92 \mathrm{~g}$ in $100 \mathrm{~mL}$ ultra-pure water, $5 \%$ Mo loading) was added to $9.5 \mathrm{~g} \mathrm{SZ}$ and the mixture was vigorously stirred for $2 \mathrm{~h}$. Excess water was removed by rotary evaporation at $353 \mathrm{~K}$, prior to drying at $393 \mathrm{~K}$ and calcination at $823 \mathrm{~K}(3 \mathrm{~h})$. This material is denoted as $5 \mathrm{MoO}_{3} / \mathrm{SZ}$. Carburisation was achieved by heating $5 \mathrm{MoO}_{3} / \mathrm{SZ}(0.2-0.7 \mathrm{~g})$ to $923 \mathrm{~K}$ at $10 \mathrm{~K} \mathrm{~min}^{-1}$ in a flow of hydrogen and then, on attaining this temperature, switching to a mixture of $\mathrm{H}_{2}: \mathrm{CH}_{4}$ (4:1) and maintaining these conditions for $4 \mathrm{~h}$. Carburised sample is denoted as $5 \mathrm{Mo}_{2} \mathrm{C} / \mathrm{SZ}$. In some cases, ex situ characterisation was performed on previously carburised sample, which was passivated by flowing $5 \% \quad \mathrm{O}_{2} / \mathrm{He}$ at room temperature ( $298 \mathrm{~K})$ for $1 \mathrm{~h}$ to prevent bulk oxidation.

\section{Characterisation}

The sulfur content of SZ was determined using a LECO CS744 analyser. The Mo loading was determined using an Agilent 4100 microwave plasma-Atomic emission spectrometer (MIP-AES) after acid digestion in a $\mathrm{HCl} / \mathrm{HNO}_{3}$ mixture. Surface area and porosity were determined using a Micromeritics TriStar instrument after sample pretreatment in a $\mathrm{N}_{2}$ flow at $473 \mathrm{~K}$ for $4 \mathrm{~h}$. TG-MS was used to probe the thermal stability of the sample and the possible gases evolved during thermal treatment. The heating rate was set at $10 \mathrm{~K} \mathrm{~min}^{-1}$ and the temperature increased from 298 to $1273 \mathrm{~K}$ in air $\left(100 \mathrm{~mL} \mathrm{~min}^{-1}\right)$.

$\mathrm{X}$-ray diffraction patterns were recorded on PANalytical X'Pert Pro diffractometer, employing $\mathrm{Cu} \mathrm{K} \alpha$ monochromatic radiation. Patterns were collected at room temperature with steps of $0.02^{\circ}$ in a range of $20^{\circ}-80^{\circ}$. The phases were identified with the aid of HighScore software. The crystalline size $(\mathrm{nm})$ was calculated from the reflection of tetragonal phase at $2 \theta$ of $30.34^{\circ}$, using the Scherrer equation [17]. The Raman spectra were recorded using a Renishaw spectrometer equipped with invia Raman microscope RE 02. 514-nm Laser was employed as the exciting source and the measuring parameters were accumulation 5, exposure time $10 \mathrm{~s}$ and laser power $50 \%$.

The morphology of the sample was investigated using scanning electron microscope ISI-ABT55, under highvacuum mode operated at $20 \mathrm{kV}$. The sample was carboncoated to prevent reflection. EDX mapping was done with ED system link analytical AN10/55S attached with ED detector link analytical LZ5. Temperature-programmed reduction study was carried out using a TPDRO 1100 (CE Instruments). Sample was exposed to a gaseous atmosphere composed of $5 \% \mathrm{H}_{2} / \mathrm{N}_{2}$ at $20 \mathrm{~mL} \mathrm{~min}{ }^{-1}$ and heating from 313 to $1273 \mathrm{~K}$ at $10 \mathrm{~K} \mathrm{~min}^{-1}$ and then holding this temperature for $40 \mathrm{~min}$. The amount of hydrogen consumed was determined relative to a copper oxide standard. The strength and nature of acid sites were determined by FTIR of pyridine adsorption using a PerkinElmer FT100 series spectrometer. The Langmuir constant and CO chemisorption capacity was determined based on data derived from 
measurements using a Micromeritics ASAP 2020-C instrument. An in situ pretreatment was performed $\left(\mathrm{H}_{2}\right.$ at $723 \mathrm{~K}$ ) on sample previously passivated as described above $\left(5 \mathrm{Mo}_{2} \mathrm{C} / \mathrm{SZ}\right)$,

\section{Catalytic activity measurement}

Conversion of heptane was carried out with a quartz reactor $(1.0 \mathrm{~cm}$ i.d., $29 \mathrm{~cm}$ long) at atmospheric pressure in the presence of hydrogen. The flow rates for the reactions were fixed to $0.5 \mu \mathrm{min}^{-1}$ and $9 \mathrm{~mL} \mathrm{~min}{ }^{-1}$ for $\mathrm{n}-\mathrm{C} 7$ and hydrogen, respectively. The effects of space velocity (varied by changing catalyst mass in the range $0.2-0.7 \mathrm{~g}$ ) and temperature $(723-873 \mathrm{~K})$ were investigated using separate reactions. The products were automatically sampled with a ten-port multi-loop VICI Valco sampling valve attached with the reaction rig and later analysed by GC (PerkinElmer 8410 fitted with a 5.6-m long $15 \%$ squalene on chromosorb WHP column and a FID). The conversion, research octane number (RON) and selectivity were calculated as follows:

$$
\begin{aligned}
& \% X=\frac{\mathrm{Xi}-\mathrm{Xf}}{\mathrm{Xi}} 100, \\
& \mathrm{RON}=\sum_{f=7}^{i=5} \frac{\mathrm{Xn}}{\mathrm{Xi}-\mathrm{Xf}} \mathrm{RON} n, \\
& \% S=\frac{\mathrm{Xn}}{\mathrm{Xi}-\mathrm{Xf}} 100,
\end{aligned}
$$

where $X$ is the conversion, $\mathrm{Xi}$ is the initial amount $(\mu \mathrm{mol})$ of heptane before reaction, $\mathrm{Xf}$ is the amount of heptane after reaction, $\mathrm{Xn}$ is the corrected amount of individual product and RON $n$ is the RON of the individual product formed. To better understand the reaction pathway and role of each detected component in the effluent stream, experimental data of selectivity as a function of conversion at fixed temperature were collected. The $y$-intercept in selectivity vs conversion plots was obtained using cubic spline extrapolation methods in which the input (experimental) data were split into a given number of components, and each segment fitted with a cubic polynomial. The second derivative of each cubic function was then set to zero. The data obtained (spline data) were plotted and shown as the continuous line which intercepts the $y$-axis at zero conversion.

\section{Results}

The XRD pattern of SZ (Fig. 1a) suggests that calcination of sulfated zirconium hydroxide at $823 \mathrm{~K}$ yields predominantly tetragonal zirconia (ICDD 01-079-1769 and 01-0791764 patterns) with a crystallite size of $3.8 \mathrm{~nm}$ (Table 1)

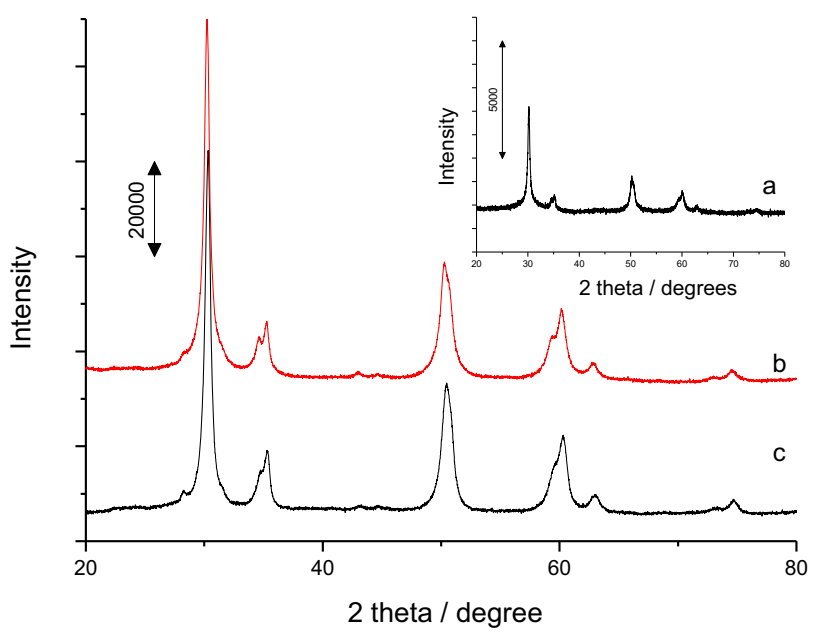

Fig. 1 XRD pattern of $a \mathrm{SZ}$ inset, $b 5 \mathrm{MoO}_{3} / \mathrm{SZ}$ and $c 5 \mathrm{Mo}_{2} \mathrm{C} / \mathrm{SZ}$

based on application of the Scherrer equation. The addition of $\mathrm{MoO}_{3}$ and subsequent carburisation treatment had little effect on the XRD patterns with no features attributable to an Mo-based phase suggesting high dispersion (Fig. 1b-c). There was also no apparent change to the zirconia crystallite size despite further thermal treatments (Table 1). SEM imaging with EDX analysis (Fig. 2) suggests the formation of large agglomerates of zirconia $(10 \mu)$ and confirms the presence of Mo. The latter was also confirmed by detection of bands due to $\mathrm{Mo}=\mathrm{O}$ and $\mathrm{Mo}-\mathrm{O}-\mathrm{Mo}$ stretching modes in Raman spectra (Fig. 3). The bands at ca. 825 and $972 \mathrm{~cm}^{-1}$ are characteristic of bridging Mo$\mathrm{O}-\mathrm{Mo}$ and terminal $\mathrm{Mo}=\mathrm{O}$ stretching modes, respectively [26, 40]. Other peaks at $147,274,313,416$, and $646 \mathrm{~cm}^{-1}$ are characteristic of tetragonal zirconia [13], consistent with XRD results (Fig. 1). The replacement/shift in the band from 972 to $1009 \mathrm{~cm}^{-1}$ could be an indication of carbide formation. However, Chary et al. [41] have reported a shift in bands from 920 to $950 \mathrm{~cm}^{-1}$ as indicative of hepta- and octamolybdates formation [41]. Bands between 900 and $1000 \mathrm{~cm}^{-1}$ have been attributed to terminal $\mathrm{Mo}=\mathrm{O}$ bonds of polymolybdate on $\mathrm{ZrO}_{2}$ [41].

The surface textural properties and chemical analysis of SZ, $5 \mathrm{MoO}_{3} / \mathrm{SZ}$ and $5 \mathrm{Mo}_{2} \mathrm{C} / \mathrm{SZ}$ are listed in Table 1 . Chemical analysis shows that the Mo loading is close to the nominal value (4.9 vs $5.0 \mathrm{wt} \%$ ). The presence of $\mathrm{MoO}_{3}$ resulted in a marked decrease in both surface area (120 vs $\left.59 \mathrm{~m}^{2} \mathrm{~g}^{-1}\right)$ and pore volume $\left(0.11 \mathrm{vs} 0.06 \mathrm{~cm}^{3} \mathrm{~g}^{-1}\right)$. This could, in principle, be attributed to particle growth or pore filling/blocking by Mo species [17]; however, the absence of crystallite growth (Table 1) infers that the latter is more plausible. Interestingly, carburisation resulted in an increase in pore size/volume, which would suggest a change to the way in which Mo was dispersed over the support (see later). The apparent surface density of Mo is expressed as the number of $\mathrm{MoO}_{3}$ units per square

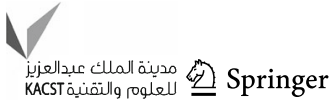


Table 1 Physical properties of $\mathrm{SZ}, 5 \mathrm{MoO}_{3} / \mathrm{SZ}$ and $5 \mathrm{Mo}_{2} \mathrm{C} / \mathrm{SZ}$

\begin{tabular}{|c|c|c|c|}
\hline Parameters & $\mathrm{SZ}$ & $5 \mathrm{MoO}_{3} / \mathrm{SZ}$ & $5 \mathrm{Mo}_{2} \mathrm{C} / \mathrm{SZ}$ \\
\hline BET surface area $\left(\mathrm{m}^{2} \mathrm{~g}^{-1}\right)$ & 120 & 59 & 45 \\
\hline Pore volume $\left(\mathrm{cm}^{3} \mathrm{~g}^{-1}\right)$ & 0.11 & 0.06 & 0.13 \\
\hline Pore size $(\mathrm{nm})$ & 2.3 & 2.7 & 5.3 \\
\hline Sulfur $(w t \%)^{a}$ & 2.0 & 1.5 & 1.1 \\
\hline Molybdenum loading (wt $\%)^{\mathrm{b}}$ & - & 4.9 & - \\
\hline Mo surface density $\left(\rho \mathrm{MoO}_{3} \text { atoms } \mathrm{nm}^{-2}\right)^{\mathrm{c}}$ & - & 3.5 & 4.6 \\
\hline Zirconia crystalline size $(\mathrm{nm})^{\mathrm{d}}$ & 3.7 & 3.8 & 3.6 \\
\hline
\end{tabular}

${ }^{a}$ Determined from combustion analysis

${ }^{\mathrm{b}}$ Determined from MIP-AES

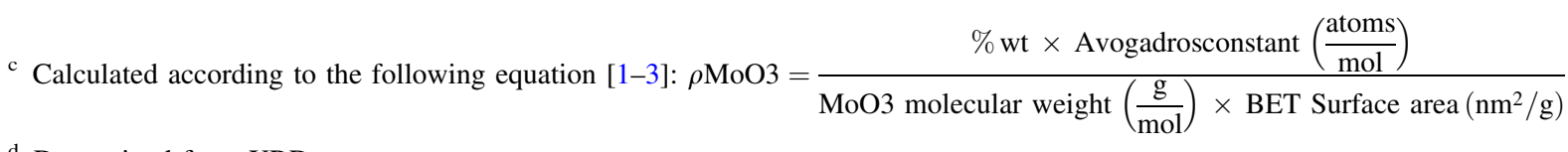

${ }^{\mathrm{d}}$ Determined from XRD

Fig. 2 SEM-EDX profile of $5 \mathrm{MoO}_{3} / \mathrm{SZ}$
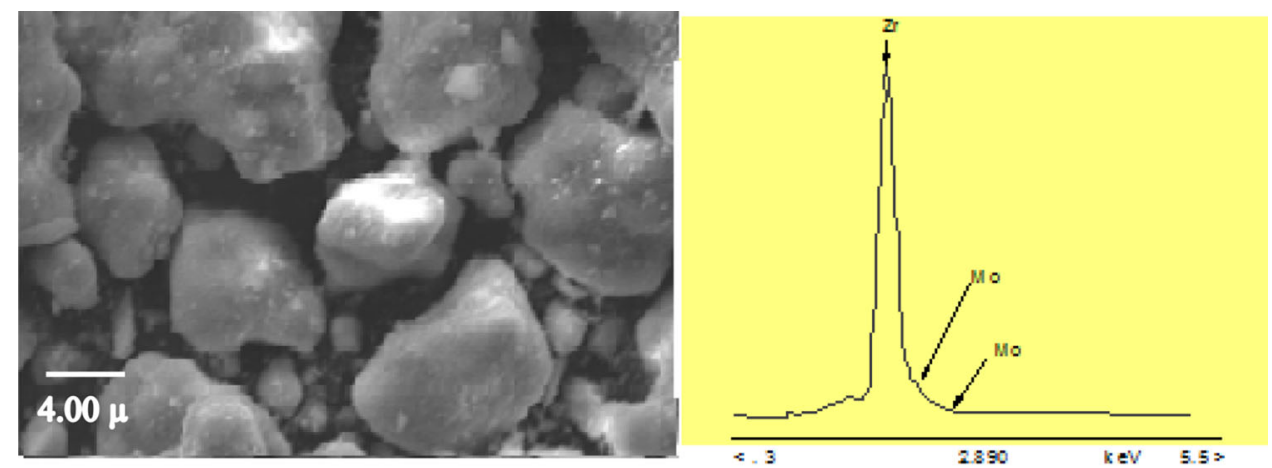

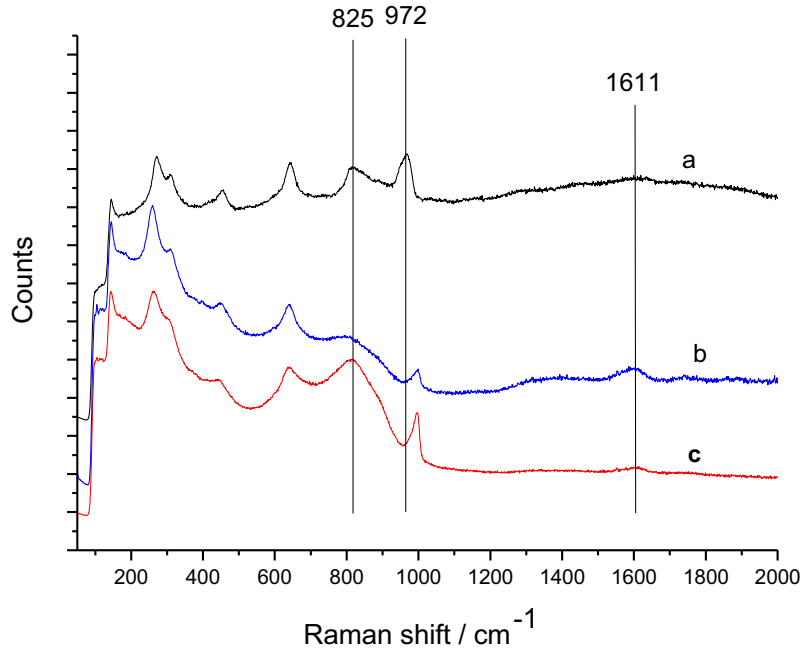

Fig. 3 Raman spectra of $a 5 \mathrm{MoO}_{3} / \mathrm{SZ}, b 5 \mathrm{Mo}_{2} \mathrm{C} / \mathrm{SZ}$ after use in n-heptane reaction and $c 5 \mathrm{Mo}_{2} \mathrm{C} / \mathrm{SZ}$

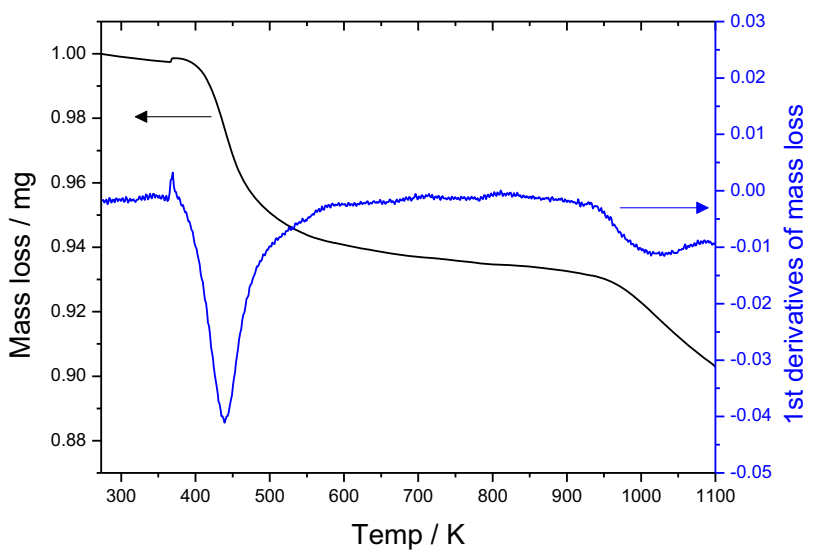

Fig. 4 TGA profile of $5 \mathrm{MoO}_{3} / \mathrm{SZ}$ 
nanometre of surface area and was calculated as 3.5, falling below the theoretical monolayer capacity of 4.9 [13].

The stability of $5 \mathrm{MoO}_{3} / \mathrm{SZ}$ was determined by TGAMS (Fig. 4) and shows weight losses at ca. 440 and $1020 \mathrm{~K}$. Based on MS analysis, the low-temperature weight loss was attributed to the loss of physisorbed water and $\mathrm{NH}_{3}$ from decomposition of residual ammonium from the Mo precursor. The high-temperature weight loss was associated with loss of sulfur (i.e., loss of SOx gases under oxidative conditions), although under other gaseous atmospheres (e.g., $\mathrm{H}_{2}$ ), the decomposition may occur at lower temperatures [42]. Loss of sulfur determined by the combustion analysis shows progressive losses induced by additional calcination and carburisation steps $(2,1.5$ and $1.1 \mathrm{wt} \%$ for $\mathrm{SZ}, 5 \mathrm{MoO}_{3} / \mathrm{SZ}$ and $5 \mathrm{Mo}_{2} \mathrm{C} / \mathrm{SZ}$, respectively—see Table 1).

Temperature-programmed reduction profiles (Fig. 5) show two major reduction stages at ca. 745 and $1136 \mathrm{~K}$. It is believed that Mo is reduced in a stepwise manner $[34,41,43]$. As such, the first reduction peak is thought to be associated with reduction of $\mathrm{Mo}^{6+}$ to $\mathrm{Mo}^{4+}$ with the high-temperature peak associated with reduction of $\mathrm{Mo}^{4+}$ to elemental Mo. SZ alone shows a single feature $>$ ca. $923 \mathrm{~K}$, while pure zirconia did not show any evidence of reduction (not shown). The total hydrogen consumption and the ratio of $\mathrm{H}_{2}$ consumed to the theoretical maximum are given in Table 2. Loading below saturation coverage had been reported to give dispersed purely tetrahedral Mo species [41], which are difficult to reduce due to the strong interaction with the support. This is consistent with the observation that the $\mathrm{H}_{2}: \mathrm{MoO}_{3}$ molar ratio for Mo loadings below $5 \mathrm{wt} \%$ over zirconia (see [44]) was all less than 1. At moderate loadings, both tetrahedral and octahedral species are present, with the latter more easily reducible [41], while at high loading, octahedral species dominate. Samples here display a value of 1.5 indicative of partial reduction of molybdenum oxide species.

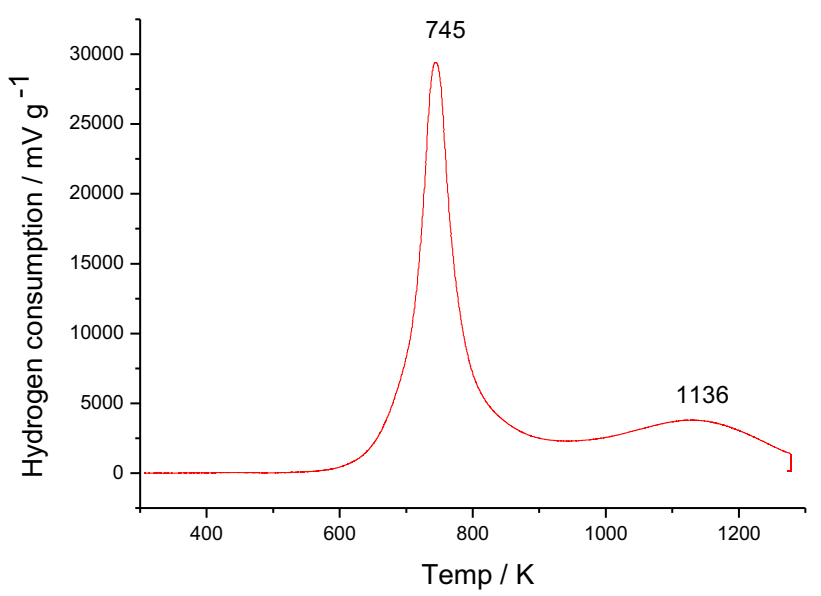

Fig. 5 TPR profile of $5 \mathrm{MoO}_{3} / \mathrm{SZ}$
Volumetric CO chemisorption yielded a type-1 isotherm (not shown) from which monolayer uptake was determined by application of the Langmuir adsorption isotherm. Uptake values most likely reflect differences in adsorption stoichiometry [45] rather than an indication of changes in dispersion. Molybdenum in an oxidised state may form dimeric and trimeric carbonyl species depending upon the oxidation state, which may explain why the $\mathrm{CO}$ uptake was almost twice for the oxide compared with the carbide (Table 2). CO may be adsorbed on transition metal either dissociative or molecularly [46, 47]. Dissociative adsorption readily occurs on early transition metals (such as molybdenum and tungsten), whereas molecular adsorption is observed for metals to the right of periodic table (e.g., Pt and $\mathrm{Ru}$ ). Lee et al. [47] observed dissociative adsorption for Mo, but molecular adsorption for carbon-modified Mo surfaces at $196 \mathrm{~K}$ (and room temperature). They have shown that for CO chemisorbed on Mo (100) with the carbon-modified Mo surfaces, adsorbed is molecular. This is because, the Mo interstices contain fourfold sites and these sites are filled first during carburisation, carbon atoms fill the interstitial sites up to one monolayer; therefore, the dissociative adsorption is completely suppressed on $\mathrm{Mo}(100)-\mathrm{C}$ at low temperatures. Hence, the presence of carbon over layers on Mo (100) reduced the propensity of Mo towards CO dissociation, leading to molecular adsorption pathways [46, 47]. Therefore, the observation here, where the oxide adsorbed more CO compared with that of carbide suggests molecular adsorption on the carbide. The Langmuir constant for the oxide was $0.16 \mathrm{mmHg}^{-1}$, while that of carbide was $0.13 \mathrm{mmHg}^{-1}$, indicating that the strength of adsorption on the oxide was greater than that of the carbide.

Acid sites for $5 \mathrm{MoO}_{3} / \mathrm{SZ}$ and $5 \mathrm{Mo}_{2} \mathrm{C} / \mathrm{SZ}$ were probed by pyridine adsorption. The samples were activated in situ for $1 \mathrm{~h}$ in air or in $\mathrm{H}_{2}$ at $773 \mathrm{~K}$ for oxide and carbide, respectively, and then outgassed under vacuum $\left(2 \times 10^{-6}\right.$ mbar) for $1 \mathrm{~h}$. The resulting absorbance bands indicate that only chemisorbed pyridine molecules were retained at this stage (not shown) with bands characteristic of coordinative adsorption on Lewis acid sites $\left(1610\right.$ and $\left.1448 \mathrm{~cm}^{-1}\right)$ and of the pyridinium ion formed by interaction with Brønsted acid sites (1638 and $1537 \mathrm{~cm}^{-1}$ ) [48]. Quantification of the amount adsorbed was derived from the integrated absorption of bands at 1537 and $1448 \mathrm{~cm}^{-1}$ and use of the molar absorption coefficients, 1.8 and $1.5 \mathrm{~cm} \mathrm{\mu mol}^{-1}$ for pyridine at Brønsted and Lewis acid sites, respectively $[49,50]$. Surprisingly, despite the loss of sulfur (Table 1), the carburised sample showed the higher Brønsted site density, while Lewis acid site density was lower for carburised sample than the oxidic form (Table 2).

The results of hydroconversion of $n$-heptane over the in situ carburised form of the catalyst are presented in this 
Table 2 Chemical properties of $5 \mathrm{MoO}_{3} / \mathrm{SZ}$ and $5 \mathrm{Mo}_{2} \mathrm{C} / \mathrm{SZ}$

\begin{tabular}{lcl}
\hline Parameters & $5 \mathrm{MoO}_{3} / \mathrm{SZ}$ & $5 \mathrm{Mo}_{2} \mathrm{C} / \mathrm{SZ}$ \\
\hline $\mathrm{CO}$ uptake $\left(\mu \mathrm{mol} \mathrm{g}{ }^{-1}\right)^{\mathrm{a}}$ & 88.19 & 51.00 \\
Langmuir constant $\left(\mathrm{Torr}^{-1}\right)^{\mathrm{a}}$ & 0.16 & 0.13 \\
$\mathrm{H}_{2}$ consumption $(\mathrm{mmol} \mathrm{g})^{-1}$ & 1.58 & - \\
$\mathrm{H}_{2} / \mathrm{MoO}_{3}^{\mathrm{b}}$ & 1.51 & - \\
Brønsted acid site density $\left(\mathrm{nm}^{2}\right)^{\mathrm{c}}$ & 0.50 & 0.56 \\
Lewis acid site density $\left(\mathrm{nm}^{2}\right)^{\mathrm{c}}$ & 0.51 & 0.33
\end{tabular}

${ }^{a}$ Based on CO chemisorption at $308 \mathrm{~K}$

b Based on hydrogen consumed during TPR

c Based on pyridine adsorption

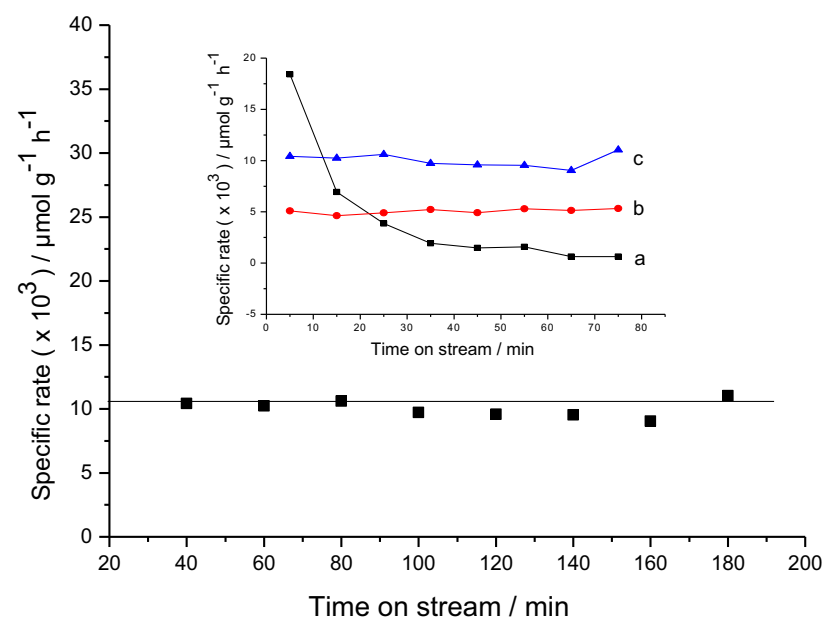

Fig. 6 n-heptane conversion rate over $3 \mathrm{~h}$ time on stream using $5 \mathrm{Mo}_{2} \mathrm{C} / \mathrm{SZ}$ sample $\left(0.3 \mathrm{~g}\right.$ catalyst, $823 \mathrm{~K}, \mathrm{H}_{2}$ flowrate of $9 \mathrm{~mL} \mathrm{~min}^{-1}$ ). In the insert, $a \mathrm{SZ}$ at $773 \mathrm{~K}, b \mathrm{SZ}$ after treatment with carburisation mixture for $4 \mathrm{~h}$ at $923 \mathrm{~K}$ and reaction temperature of $823 \mathrm{~K}, c 5 \mathrm{Mo}_{2} \mathrm{C} / \mathrm{SZ}$ under the same conditions as $b$

section. n-Heptane was selected due to the challenges in obtaining a catalyst which avoids excessive cracking [51]. One of the major issues related to the use of sulfated zirconia catalyst is that deactivation often occurs after a few minutes of reaction. Plots of conversion as a function of time are shown in (Fig. 6) for the support (SZ) and supported $\left(5 \mathrm{Mo}_{2} \mathrm{C} / \mathrm{SZ}\right)$ catalyst. The insert shows data for catalysts that were tested for short reaction times (75 $\mathrm{min}$ ). The SZ support with no pretreatment deactivated quickly and became stable after $25 \mathrm{~min}$ on stream, but with a conversion of only ca. $4 \%\left(0.6 \times 10^{-3} \mu \mathrm{mol} \mathrm{g}^{-1} \mathrm{~h}^{-1}\right)$ (Fig. 6). The deactivation could be due to coke deposition on acidic sites following multiple cracking [52]. The results for carburised support and supported catalyst are given in Fig. $6 \mathrm{~b}$ and c, respectively. Support and supported catalyst were treated in the same way. Both were subjected to a carburisation mixture for $4 \mathrm{~h}$ prior to reaction at $823 \mathrm{~K}$. No deactivation was observed for either support or supported

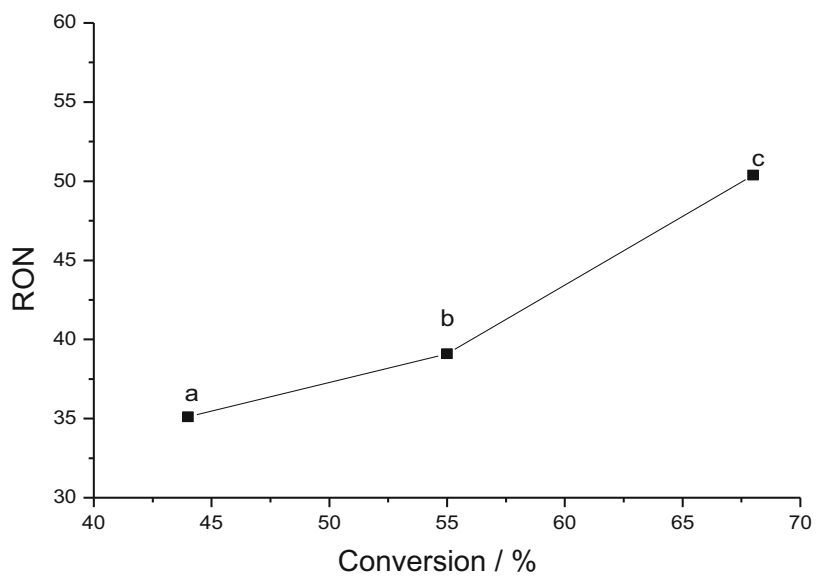

Fig. 7 RON for products produced over $5 \mathrm{Mo}_{2} \mathrm{C} / \mathrm{SZ}$ at $873 \mathrm{~K}$ as a function of conversion (varied by changing WHSV). $a$ 0.068, $b 0.041$ and $c 0.034 \mathrm{~h}^{-1}$

catalyst. However, the steady-state activity of $5 \mathrm{Mo}_{2} \mathrm{C} / \mathrm{SZ}$ was greater than that of SZ when the two are compared simply on a per gram basis. The low specific rate (steady state) for n-heptane conversion over SZ compared to $5 \mathrm{Mo}_{2} \mathrm{C} / \mathrm{SZ}$ can be because of absence of hydrogenation/ dehydrogenation centres for the former [52]. The initial rate of n-heptane conversion was higher over SZ than $5 \mathrm{Mo}_{2} \mathrm{C} / \mathrm{SZ}$. The difference observed in the initial rate and the steady rate over SZ was due to rapid deactivation of sulfate sites, which may be avoided by a balancing of the extent of reaction taking place over supported material by reaction over both types of active site and potentially by a hydrogenation of coke formed by hydrogen supplied by the active carbide phase. An explanation for the difference between the initial activity of SZ compared to that of $5 \mathrm{Mo}_{2} \mathrm{C} / \mathrm{SZ}$ could be related to the fact that during the preparation procedure and/or the additional thermal treatments experienced by the supported Mo catalyst, the number and/or nature of the supported sulfate (Tables 1,2) was modified in such a way as to render the support less active for heptane cracking. The stability of $5 \mathrm{Mo}_{2} \mathrm{C} / \mathrm{SZ}$ catalyst on stream over longer reaction times is shown in Fig. 6. This catalyst was stable for more than $3 \mathrm{~h}$ on stream and gave ca. $23 \%$ conversion $\left(1.0 \times 10^{-2} \mu \mathrm{mol} \mathrm{g}^{-1} \mathrm{~h}^{-1}\right)$ at $823 \mathrm{~K}$. In the presence of hydrogen and an active hydrogenation/dehydrogenation function, it is suggested that carbonaceous laydown is limited or avoided [53].

Figure 7 shows RON as a function of conversion. Conversion, as expected, was inversely proportional to WHSV. The RON increased as a function of conversion. Therefore, low WHSV gave the best RON and conversion when other reaction variables were held constant. Increases in contact time led to enhanced fractions of $\mathrm{C} 5+$ (pentane and higher n-alkanes) which contributed to the RON yield. However, further increases in conversion may not result in 
any significant increase in RON, since ultimately products $<$ C5 will dominate due to consecutive cracking reactions.

The effect of WHSV on product distribution is given in Fig. 8. At high space velocity $\left(0.068 \mathrm{~h}^{-1}\right)$, the major product was ethane at ca. $40 \%$ selectivity followed by pentane and iso-pentane, propane, iso-butane and other products including isomers of heptane and hexane. The product distribution suggests that terminal hydrogenolysis alone is not responsible, which under ideal situation should
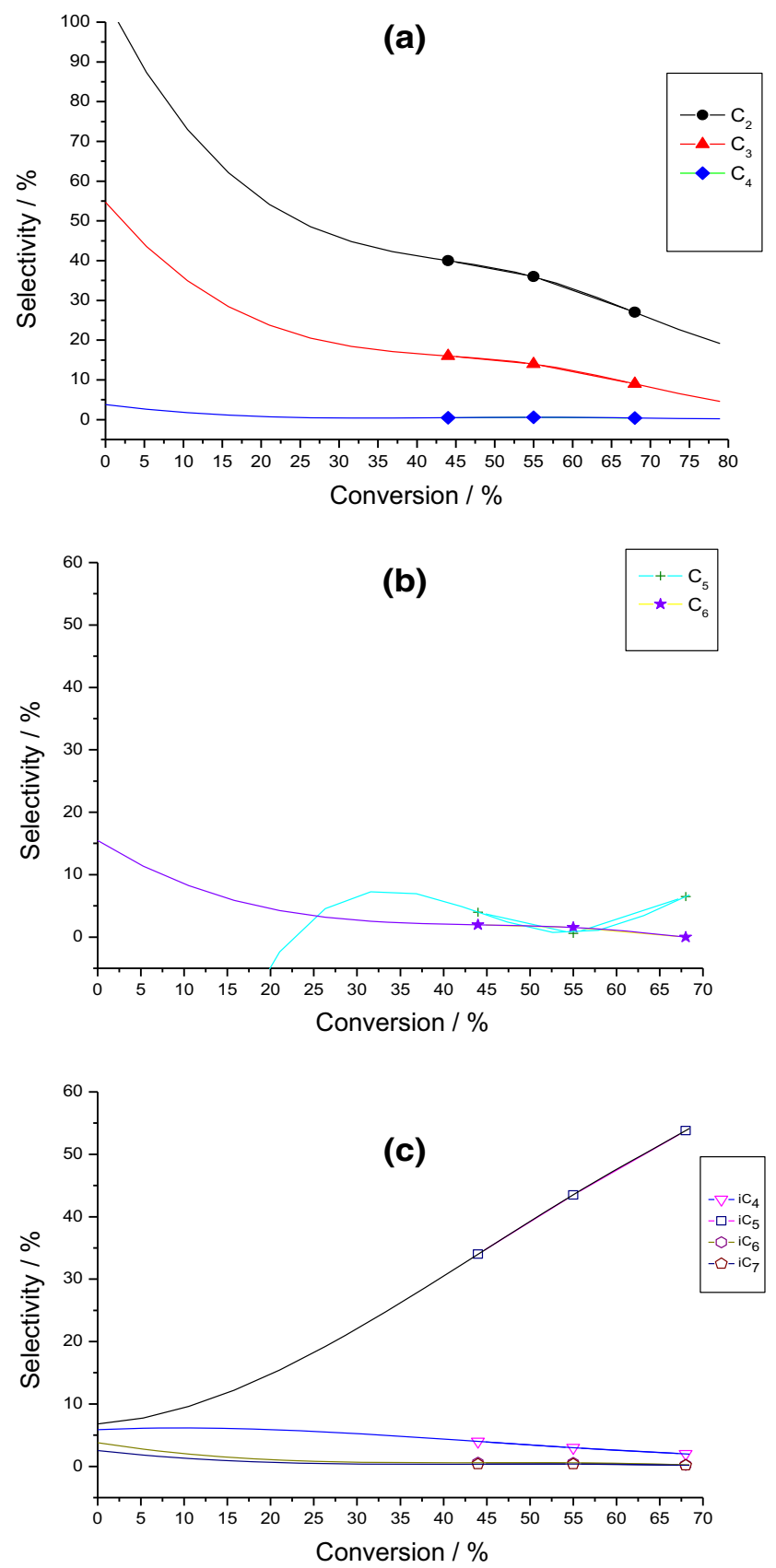

Fig. 8 Product selectivity produced over $5 \mathrm{Mo}_{2} \mathrm{C} / \mathrm{SZ}$ at $873 \mathrm{~K}$ as a function of WHSV; a light linear alkanes, $\mathbf{b}$ pentane and hexane and c iso-alkanes produce equimolar amount of methane and hexane. However, under more severe conditions of higher temperature and longer contact times, both terminal hydrogenolysis and isomerisation products can undergo secondary reactions [35]. In the case of terminal hydrogenolysis, the hexane produced can undergo hydroisomerisation, from which pentane and iso-pentane may be generated. In such a scenario, where hexane is being converted, either pentane or iso-pentane will increase at the expense of hexanes, but in this situation, ethane and iso-pentane were the major products (Fig. 8). Isomerisation products such as iso-heptane can also undergo secondary reaction by undergoing $\beta$ scission [54]. As the WHSV decreased from 0.068 to $0.034 \mathrm{~h}^{-1}$, the amount of ethane decreased from ca. 40 to $29 \%$, while in contrast, the selectivity to iso-pentanes increased from ca. 20 to ca. $55 \%$. There are many criteria to assess the reaction network [55, 56], but the most common are those used by Wojciechowski and co-workers [57-59] and the deplot method [60]. The deplot method is valid for any reaction rate law and separates primary from non-primary products [60]. The initial rate of formation of primary product is finite; hence, deplot gives a finite intercept. The deduction of deplot intercepts implies the extrapolation of data, because kinetic information is always attained at finite conversion. The spline point provided in Figs. 8 and 10 gives the extrapolated data points. Figure $8 \mathrm{a}-\mathrm{c}$ shows a finite intercept for all products with the exception of pentane. This suggests that iso-heptanes may be one of the primary products, which were not energetically favourable at the reaction temperature $(873 \mathrm{~K})$. They may undergo cracking and subsequent isomerisation to generate iso-pentane. It has been widely reported that higher alkanes have a tendency to crack during acidcatalysed reactions, because both hydrocracking and hydroisomerisation share a common intermediate, such as protonated cyclopropane [61, 62]. Therefore, formation of hydrocracked products may originate from the common intermediate and from the iso-heptane.

A plot of RON as a function of temperature is given in Fig. 9. RON for unconverted heptane is 0 , but the RON increased with conversion until a maximum at ca. 45 at $823 \mathrm{~K}$, and then decreased to ca. 35. Oloye et al. [35] observed an increase in RON with conversion due to increase in iso-pentane selectivity when n-heptane was converted between 723 and $873 \mathrm{~K}$. This iso-pentane was proposed to be formed either through cracking of the isoheptane or through the intermediate (Scheme 1 in Ref. [35]). It is worth nothing that selectivity to iso-heptane decreases as conversion increased (Fig. 10). Hence, the significant decrease in iso-heptane selectivity at higher conversion might be responsible for the decrease in RON. To understand the influence of temperature on product distribution, temperatures were varied between 723 and 


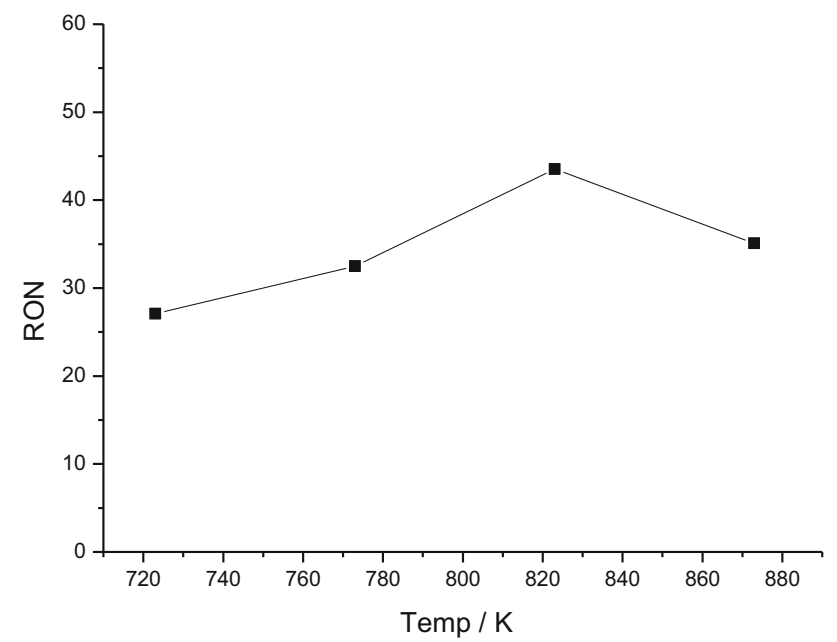

Fig. $9 \mathrm{RON}$ for products produced over $5 \mathrm{Mo}_{2} \mathrm{C} / \mathrm{SZ}$ at WHSV of $0.068 \mathrm{~h}^{-1}$ and $\mathrm{H}_{2}$ flowrate of $9 \mathrm{~mL} \mathrm{~min}^{-1}$

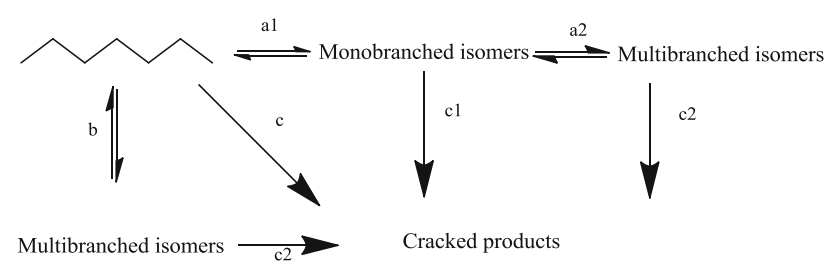

Scheme 1 Reaction pathways showing both consecutive and parallel reactions

$873 \mathrm{~K}$, while maintaining all other parameters constant at $0.068 \mathrm{~h}^{-1}$ with a hydrogen flow rate of $9 \mathrm{~mL} \mathrm{~min}^{-1}$. In this temperature range, no methane was detected, but a considerable amount of ethane was produced (Fig. 10). Ethane selectivity increased with temperature, from ca. 25 to $45 \%$, then dropped to ca. $40 \%$ as the temperature increased from 723 to $873 \mathrm{~K}$. The extrapolated data (spline points) (Fig. 10a-c) show that ethane, propane, iso-butane, pentane, hexane, iso-hexane and iso-heptanes have finite intercept. At low conversion, the selectivity to iso-heptane and propane was ca. $20 \%$, but both decreased as the conversion increased with the decrease in iso-heptane being more pronounced. Iso-heptanes decreased as the temperature increased supporting the idea that iso-heptanes are thermodynamically unfavourable at high temperature. Selectivity to iso-pentane was low at low conversion (giving a negative intercept upon extrapolation), but increased with conversion indicating that iso-pentane was mainly formed from other products. Surprisingly, pentanes decreased as the amount of iso-pentane increased suggesting that pentanes isomerised to iso-pentanes. It is clear from Fig. 10 that working at lower temperature favours isomerisation and that under more severe conditions, it is difficult to attain very high selectivity to iso-heptanes. Also of significance is that iso-heptanes, hexane, iso-hexanes, (a)
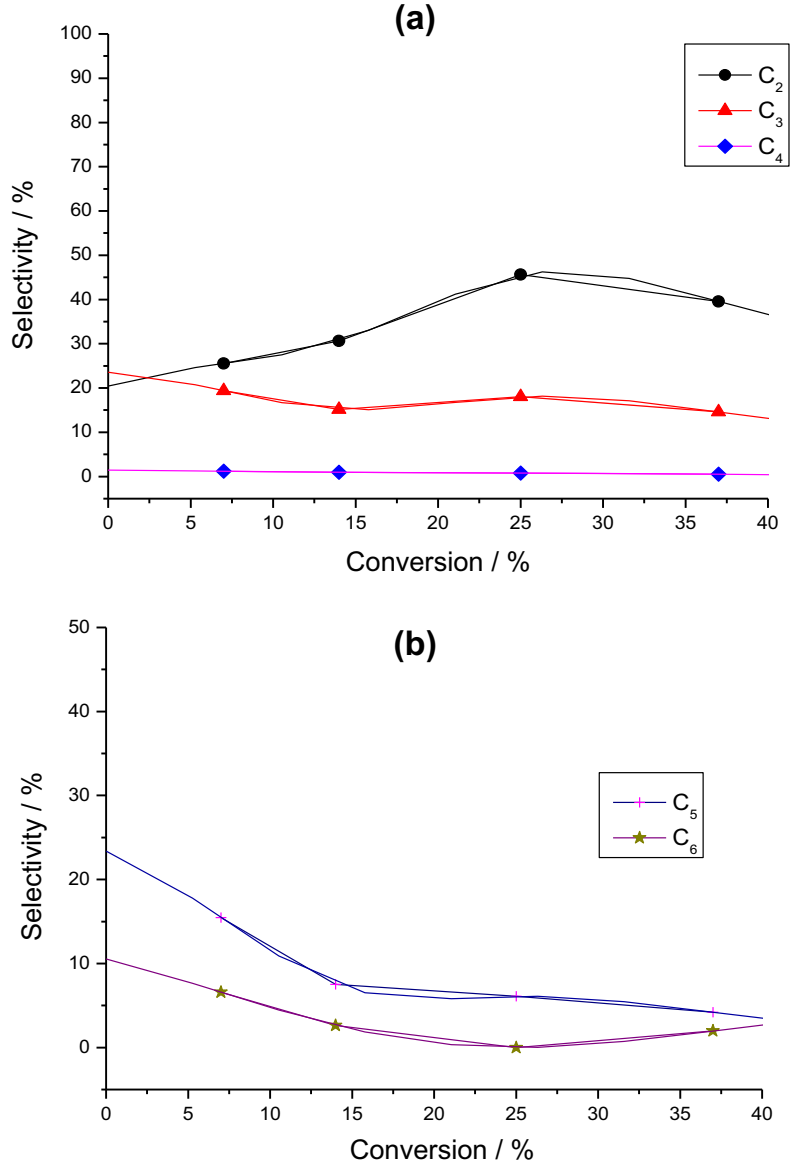

(c)

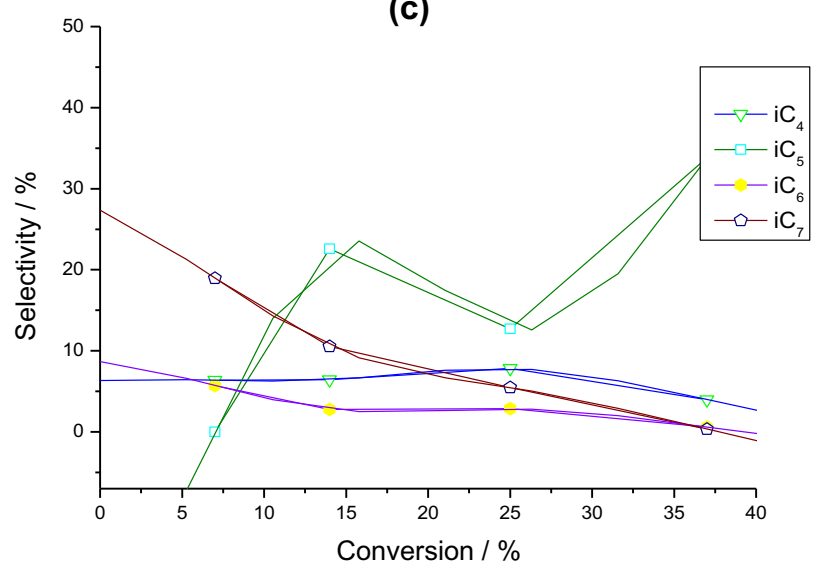

Fig. 10 Product selectivity produced over $5 \mathrm{Mo}_{2} \mathrm{C} / \mathrm{SZ}$ at WHSV of $0.068 \mathrm{~h}^{-1}$ and $\mathrm{H}_{2}$ flowrate of $9 \mathrm{~mL} \mathrm{~min}^{-1}$ as a function of conversion when temperature was varied between 723 and $873 \mathrm{~K}$; a light linear alkanes, $\mathbf{b}$ pentane and hexane and $\mathbf{c}$ iso-alkanes

pentanes and propane decreased as the temperature is increased, while ethane and iso-pentanes increased. This suggests a route involving cracking of iso-heptanes into lower molecular weight molecules, which in turn cracked (Scheme 1 route f, Ref. [35]) due to the influence of the reaction temperature $(873 \mathrm{~K})$, because high temperature 
could open other reaction routes [35]. In the study of selectivity of $\mathrm{MoO}_{3}$-catalysed C6-C7 hydroisomerisation, Garcia-Gutierrez et al. [63] observed that in addition to production of hydrocracked products from consecutive reactions of n-heptane, parallel reaction pathways also existed and the authors concluded that hydroisomerisation of n-heptane mainly leads to $\mathrm{C} 4, \mathrm{C} 3$ and $\mathrm{C} 2$ in the ratio of 1:2.2:2, respectively [63]. Therefore, the conversion of n-heptane over $\mathrm{Mo}_{2} \mathrm{C} / \mathrm{SZ}$ may be occurring on both consecutive and parallel routes simultaneously.

\section{Discussion}

To avoid significant loss of surface area due to agglomeration, and pore plugging during loading of $\mathrm{MoO}_{3}$, calcination and carburisation, a high initial dispersion is desired. The sample was calcined at $823 \mathrm{~K}$ for $3 \mathrm{~h}$ before and after incorporation of $\mathrm{MoO}_{3}$. The carburisation temperature was limited to $923 \mathrm{~K}$ to avoid excessive sulfate loss and transformation of zirconia from tetragonal to either monoclinic or cubic phase. The tetragonal phase of zirconia and well-dispersed metal oxide is essential for the catalytic activity of zirconia [64]. Above ca. $923 \mathrm{~K}$, weight losses due to sulfate removal occurred (Fig. 4), in agreement with previous studies $[65,66]$. The initial activity of SZ was higher than $5 \mathrm{Mo}_{2} \mathrm{C} / \mathrm{SZ}$, but decreases significantly, as reactions proceed. This deactivation may be due to carbonaceous deposit on the SZ due to the absence of a hydrogenating function that assisted in removing cokeforming precursors.

The pore size distribution and adsorption isotherm for SZ was similar to the uncarburised catalyst sample (not shown), although the carburised catalyst sample $\left(5 \mathrm{Mo}_{2} \mathrm{C} /\right.$ SZ) has increased mesoporosity as seen in the wide hysteresis, characteristic of mesoporous material. This development of mesoporosity may be beneficial for catalyst stability and hydroconversion of n-heptane. Hydroconversion of n-alkane over mesoporous has been reported to be beneficial for obtaining high yields of mono- and branched alkanes due to the ease of diffusion through the pore network [6]. Lack of mesoporosity in the sulfated zirconia and uncarburised catalyst may contribute to the rapid deactivation experienced by these samples.

Converting n-heptane, which has no contribution to RON of fuel, is necessary because the average RON obtained after direct fractional distillation of crude oil into light naphtha without any modification is 65 and the average requirement is 95-98. In their review, Valavarasu and Sairam [67] concluded that isomerisation of light naphtha streams rich in pentanes and hexanes typically results in an increase of 10-22 RON. Hence, converting from 0 RON to ca. 20 to 50 is significant, since this will increase the total RON. For this purpose, RON was calculated from the conversion of n-heptane by changing temperature and WHSV. Working at very low temperature $(<423 \mathrm{~K})$ will increase the selectivity to iso-heptanes, because they are thermodynamically favourable and stable at such low temperature, but it has disadvantage of producing low yield. Mihályi et al. [51] have suggested that hydrocracking is not negligible at high conversions level, but high conversion can only be achieved either at high temperature or at low WHSV. The observation is consistent with the data obtained in this research.

The influence of conversion on RON was monitored by varying WHSV and temperature. RON increased with conversion since as n-heptane was consumed, the fraction of $\mathrm{C} 5+$ increased. Iso-pentanes increased as the WHSV decreased, suggesting that more of the primary reaction products were converted to secondary products. Scheme 1 shows multiple ways in which n-heptane conversion could end in high selectivity to cracked products. Jacobs and coworkers reported that selectivity to cracked products increased with conversion for n-alkane hydroisomerisation over various Pd loading on H-beta zeolite [68]. C2 and iC5 were the major products at low conversion followed by $\mathrm{C} 3$ and iC4, with $\mathrm{C} 2$ in excess of iC5 and C3 in excess of iC4. It could be said that the path that leads to formation of the products was not limited by the classical hydrocracking pathway in which an equimolar amount of the direct cracking products such as $\mathrm{C} 3$ and $\mathrm{iC} 4$ would be obtained. Blomsma et al. [69] obtained excesses of C4 compared to $\mathrm{C} 3$ in conversion of heptane and concluded that this was the result of other reaction routes different from classical hydrocracking pathway. At high conversion, iC5 and C2 were still the major products, but iC5 was now in excess of C2 (Fig. 8). Busto et al. [1] observed a decrease in the yield of iso-alkane with increased temperature. Galadima et al. [6] reported a slight loss in hydroisomerisation selectivity due to secondary reactions when the temperature was raised from 623 and $723 \mathrm{~K}$. However, they obtained a significant decrease in hydroisomerisation selectivity when 2-methylheptane was reacted over carbided molybdena on sulfated zirconia with isomer selectivity low at $673 \mathrm{~K}$ and dropping to zero at $723 \mathrm{~K}$. Hence, the product distribution in this research was related to reaction pathway described in Scheme 1. The influence of temperature in the products distribution was well defined in Fig. 10 as the selectivity to iso-heptanes decreased as the conversion increased. As the temperature increases, multiple cracking occurs which favours ethane and iso-pentanes as products.

A classical hydroisomerisation reaction is believed to occur over a bifunctional catalyst which contains an appropriate balance between acid and metal sites [1, 6]. When $\mathrm{n}-\mathrm{C} 7$ is converted over a catalyst with an incongruity between acid/metals sites, the cracked products ranged

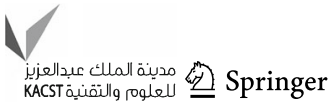


between $\mathrm{C} 3$ and $\mathrm{C} 6$, whereas on a catalyst with a balance of metal/acid sites, the cracked products is limited to only C3 and C4 [69]. Hence, the range of hydrocracked product obtained in this research may signify that the ratio of metal site to acid sites was not fully optimised. Catalyst here contained both metal-like hydrogenation sites (51 $\mu \mathrm{mol} \mathrm{g}^{-1}$ from CO adsorption) and Brønsted acid sites (42 $\mu \mathrm{mol} \mathrm{g}^{-1}$ pyridine retained) giving a ratio of 1.22 , which is greater than the range of 0.03 and 0.17 reported to be indicative of low and high hydrogenating/acid site density ratios, respectively, for hydroisomerisation of n-alkanes over PtHFAU [70]. It had been reported that catalysts with a high degree of hydrogenation activity and low degree of acidity are best for maximising the extent of hydroisomerisation vs hydrocracking [71] and for avoiding deactivation due to coking [54]. The lack of deactivation through coking (Fig. 6) suggests that the catalyst possessed enough carbide sites in relation to the acid site to minimise build-up of carbonaceous precursors. However, these ratios also fail to distinguish between the relative rates on these sites, and so, the relatively high density of metal-like sites $\left(51 \mu \mathrm{mol} \mathrm{g}^{-1}\right)$ compared to Brønsted acid sites (42 $\mu \mathrm{mol} \mathrm{g}^{-1}$ ) may not fully explain the low yield of the heptane isomers.

Busto and co-workers [1] reported that if the reaction temperature or pressure were varied independently, then the best $\mathrm{RON}$ gain to $\mathrm{C} 1-\mathrm{C} 4$ (methane to butane) ratio would be obtained at high temperature or pressure. This observation is consistent with the data displayed in Fig. 9, where the RON produced increased as temperature increases until $823 \mathrm{~K}$ after which the RON reduced. The decrease in RON arises as significant iso-heptane cracking takes place above $823 \mathrm{~K}$. It was observed that RON decreased as the WHSV increased; the reaction is under kinetic control and the selectivity to each product is influenced by a change in WHSV. WHSV of $0.034 \mathrm{~h}^{-1}$ produced the distribution with highest iso-C5-7 (isomers of pentane, hexane and heptane) fraction and, hence, the highest RON. It is worth noting that calculation in RON is a better method of presenting hydroconversion data compared to just isomer selectivity, because it takes into account other products that are part of fuel constituent and with high RON value. For example, the RON of 2,3dimethylbutane is 103.5 which is better than an average RON that can be obtained from most heptane isomers.

\section{Conclusion}

This catalyst was synthesized using low loading of $\mathrm{MoO}_{3}$ (5 weight $\%$ of $\mathrm{MoO}_{3}$ ) on sulfated zirconia. n-heptane RON was converted from 0 to ca. 20-50 using $\beta-M o 2 C / S Z$. The incorporation of $\mathrm{Mo}_{2} \mathrm{C}$ carbide into $\mathrm{SZ}$ has synergetic effect as it improves its stability and activity. Integration of low loading prevents aggregation of supported particles that can lead to sintering and significant loss of surface area. The carbide is well dispersed and this provides mesoporosity, which enhanced the stability and conversion.

It was observed that RON increased with conversion when WHSV and temperature were varied independently, while keeping other parameters constant. Also, RON increased with conversion up to $823 \mathrm{~K}$ and then decreased when temperature was varied due to significant decrease in iso-heptane selectivity. It can be concluded that temperature and WHSV affect conversion, which in turn affects RON. WHSV and temperature also affect the product selectivity, and multiple cracking occurs at high temperature and low WHSV.

Open Access This article is distributed under the terms of the Creative Commons Attribution 4.0 International License (http:// creativecommons.org/licenses/by/4.0/), which permits unrestricted use, distribution, and reproduction in any medium, provided you give appropriate credit to the original author(s) and the source, provide a link to the Creative Commons license, and indicate if changes were made.

\section{References}

1. Busto M, Grau J, Vera C (2010) Screening of optimal pretreatment and reaction conditions for the isomerization-cracking of long paraffins over $\mathrm{Pt} / \mathrm{WO}_{3}-\mathrm{ZrO}_{2}$ catalysts. Appl Catal A: Gen 387:35-44

2. Boulter P, Latham S (2009) Emission factors: report 5-a review of the effects of fuel properties on road vehicle emissions

3. Mackinven R, Hublin M (1996) European programme on emissions, fuels and engine technologies (EPEFE) - gasoline aromatics/e100 study. SAE Int. doi:10.4271/961065

4. Ono Y (2003) A survey of the mechanism in catalytic isomerization of alkanes. Catal Today 81:3-16

5. Matsuda T, Ohno T, Hiramatsu Y, Li Z, Sakagami H, Takahashi $\mathrm{N}$ (2009) Effects of the amount of MoO3 on the catalytic properties of $\mathrm{H}_{2}$-reduced $\mathrm{Pt} / \mathrm{MoO}_{3}-\mathrm{SiO}_{2}$ for heptane isomerization. Appl Catal A: Gen 362:40

6. Galadima A, Wells RPK, Anderson JA (2012) n-Alkane hydroconversion over carbided molybdena supported on sulfated zirconia. Appl Petrochem Res 1:35

7. Galadima A, Anderson J, Wells R (2009) Solid acid catalysts in heterogeneous $n$-alkanes hydroisomerisation for increasing octane number of gasoline. Sci World J 4:15-22

8. Arata K, Matsuhashi H, Hino M, Nakamura H (2003) Synthesis of solid superacids and their activities for reactions of alkanes. Catal Today 81:17-30

9. Hino M, Arata K (1988) Synthesis of solid superacid of tungsten oxide supported on zirconia and its catalytic action for reactions of butane and pentane. $\mathrm{J}$ Chem Soc Chem Commun 18:1259-1260

10. Hino M, Arata K (1980) Synthesis of solid superacid catalyst with acid strength of $\mathrm{Ho} \leq 16.04$. J Chem Soc Chem Commun 851

11. Arata K, Hino M (1990) Solid catalyst treated with anion-XVIII. Benzoylation of toluene with benzoyl chloride and benzoic anhydride catalysed by solid superacid of sulphate-supported alumina. Appl Catal 59:197 
12. Yori JC, Pieck CL, Parera JM (2000) Acid or bifunctional mechanism in paraffin isomerization reaction on $\mathrm{Pt} / \mathrm{SO} 42-\mathrm{ZrO} 2$ and $\mathrm{Pt} / \mathrm{WO} 3-\mathrm{ZrO} 2$ catalysts. Stud Surf Sci Catal 130C:2441

13. Xie S, Chen K, Bell AT, Iglesia E (2000) Structural characterization of molybdenum oxide supported on zirconia. J Phys Chem B 104:10059

14. Vera C, Yori J, Parera J (1998) Redox properties and catalytic activity of $\mathrm{SO}_{2}-\mathrm{ZrO}_{2}$ catalysts for n-butane isomerization Role of transition metal cation promoters. Appl Catal A: Gen 167:75

15. Comelli RA, Vera CR, Parera JM (1995) Influence of $\mathrm{ZrO}_{2}$ crystalline structure and sulfate ion concentration on the catalytic activity of $\mathrm{SO}_{4}{ }^{2-}-\mathrm{ZrO}_{2}$. J Catal 151:96

16. Perret N, Wang X, Delannoy L, Potvin C, Louis C, Keane MA (2012) Enhanced selective nitroarene hydrogenation over $\mathrm{Au}$ supported on $\beta-\mathrm{Mo}_{2} \mathrm{C}$ and $\beta-\mathrm{Mo}_{2} / \mathrm{Al}_{2} \mathrm{O}_{3}$. J Catal 286:172

17. El-Sharkawy EA, Khder AS, Ahmed AI (2007) Structural characterization and catalytic activity of molybdenum oxide supported zirconia catalysts. Microporous Mesoporous Mater $102: 128$

18. Levy R, Boudart M (1973) Platinum-like behavior of tungsten carbide in surface Catalysis. Science 181:547

19. Ted Oyama S (1992) Crystal structure and chemical reactivity of transition metal carbides and nitrides. J Solid State Chem 96:442

20. Matsuda T, Sakagami H, Takahashi N (2001) Thermal stability of porous $\mathrm{MoOx}$ and its catalytic property for the conversion of 2-propanol. Appl Catal A: Gen 213:83

21. Chen K, Xie S, Iglesia E, Bell AT (2000) Structure and properties of zirconia-supported molybdenum oxide catalysts for oxidative dehydrogenation of propane. J Catal 189:421

22. Tshabalala TE, Coville NJ, Anderson JA, Scurrell MS (2015) Dehydroaromatization of methane over $\mathrm{Sn}-\mathrm{Pt}$ modified $\mathrm{Mo} / \mathrm{H}-$ ZSM-5 zeolite catalysts: effect of preparation method. Appl Catal A: Gen 503:218

23. Oshikawa K, Nagai M, Omi S (2001) Characterization of molybdenum carbides for methane reforming by TPR, XRD, and XPS. J Phy Chem B 105:9124

24. Brungs AJ, York AP, Claridge JB, Márquez-Alvarez C, Green ML (2000) Dry reforming of methane to synthesis gas over supported molybdenum carbide catalysts. Catal Lett 70:117-122

25. Posada-Pérez S, dos Santos Politi JR, Viñes F, Illas F (2015) Methane capture at room temperature: adsorption on cubic $\delta$ $\mathrm{MoC}$ and orthorhombic $\beta-\mathrm{Mo}_{2} \mathrm{C}$ molybdenum carbide (001) surfaces. RSC Adv 5:33737

26. Brown ASC, Hargreaves JSJ, Taylor SH (1999) A study of "superacidic" $\mathrm{MoO}_{3} / \mathrm{ZrO}_{2}$ catalysts for methane oxidation. Catal Lett 57:109

27. Tatsumi T, Muramatsu A, Tominaga H (1987) Supported molybdenum catalysts for alcohol synthesis from $\mathrm{CO}-\mathrm{H}_{2}$. Appl Catal 34:77

28. Li X, Feng L, Liu Z, Zhong B, Dadyburjor DB, Kugler EL (1998) Higher alcohols from synthesis gas using carbon-supported doped molybdenum-based catalysts. Ind Eng Chem Res 37:3853

29. Fürstner A, Mathes C, Lehmann CW (2001) Alkyne metathesis: development of a Novel molybdenum-based catalyst system and its application to the total synthesis of epothilone A and C. Chem Eur J 7:5299

30. Mo T, Xu J, Yang Y, Li Y (2016) Effect of carburization protocols on molybdenum carbide synthesis and study on its performance in CO hydrogenation. Catal Today 261:101

31. Saito M, Anderson RB (1980) The activity of several molybdenum compounds for the methanation of CO. J Catal 63:438

32. Łaniecki M, Małecka-Grycz M, Domka F (2000) Water-gas shift reaction over sulfided molybdenum catalysts: I. Alumina, titania and zirconia-supported catalysts. Appl Catal A: Gen 196:293
33. Galadima A (2012) Development of new and improved catalysts for the isomerization of refinery products. $\mathrm{PhD}$ thesis, University of Aberdeen

34. Galadima A, Wells RPK, Anderson JA (2012) Hydroconversion of $n$-alkanes over carbided $\mathrm{Rh} /$ molybdena zirconia catalysts. Top Catal 55:931

35. Oloye FF, McCue AJ, Anderson JA (2016) Understanding reaction processes for $\mathrm{n}$-heptane over $10 \mathrm{Mo}_{2} \mathrm{C} / \mathrm{SZ}$ catalyst. Catal Today 277:246

36. Vrinat M, Hamon D, Breysse M, Durand B, Des Courieres T (1994) Zirconia-and alumina-supported molybdenum-based catalysts: a comparative study in hydrodesulfurization and hydrogenation reactions. Catal Today 20:273

37. Ledoux MJ, Pham-Huu C, York APE, Blekkan EA, Delporte P, Del Gallo P (1996) Study of the isomerization of $\mathrm{C}_{6}$ and $\mathrm{C}_{6+}$ alkanes over molybdenum oxycarbide catalysts. In: Oyama ST (ed) The chemistry of transition metal carbides and nitrides, Blackie, New York, p 373

38. Lee JS, Locatelli S, Oyama ST, Boudart M (1990) Molybdenum carbide catalysts 3 . Turnover rates for the hydrogenolysis of n-butane. J Catal 125:157

39. Matsuda T, Sakagami H, Takahashi N (2003) $\mathrm{H}_{2}$-reduced Pt/ $\mathrm{MoO}_{3}$ as a selective catalyst for heptane isomerization. Catal Today $81: 31$

40. Sohn JR, Chun EW, Paet YI (2003) Spectroscopic studies on $\mathrm{ZrO}_{2}$ modified with $\mathrm{MoO}_{3}$ and activity foracid catalysis. Bull Korean Chem Soc 24:1785

41. Chary KVR, Reddy KR, Kishan G, Niemantsverdriet JW, Mestl G (2004) Structure and catalytic properties of molybdenum oxide catalysts supported on zirconia. J Catal 226:283

42. Iglesia E, Soled SL, Kramer GM (1993) Isomerization of alkanes on sulfated zirconia: promotion by $\mathrm{Pt}$ and by adamantyl hydride transfer species. J Catal 144:238

43. Orehotsky J, Jamiolkowski L, Gerboc J (1979) The hydrogen reduction of $\mathrm{MoO}_{3}$ powder to $\mathrm{MoO}_{2}$. Mater Sci Eng 41:237

44. Oloye FF (2016) Synthesis and characterisation of zirconia supported molybdenum carbide catalysts for hydroconversion of n-heptane. PhD thesis, University of Aberdeen

45. Lee J, Oyama S, Boudart M (1987) Molybdenum carbide catalysts: I. Synthesis of unsupported powders. J Catal 106:125

46. Clair TPS, Oyama ST, Cox DF (2000) CO and $\mathrm{O}_{2}$ adsorption on $\alpha-\mathrm{Mo}_{2} \mathrm{C}(0001)$. Surf Sci 468:62

47. Lee JS, Lee KH, Lee JY (1992) Selective chemisorption of carbon monoxide and hydrogen over supported molybdenum carbide catalysts. J Phys Chem 96:362

48. Bachiller-Baeza B, Anderson JA (2004) FTIR and reaction studies of the acylation of anisole with acetic anhydride over supported HPA catalysts. J Catal 228:225

49. Khabtou S, Chevreau T, Lavalley JC (1994) Quantitative infrared study of the distinct acidic hydroxyl groups contained in modified Y zeolites. Microporous Mater 3:133

50. Tran M-, Gnep NS, Szabo G, Guisnet M (1998) Influence of the calcination temperature on the acidic and catalytic properties of sulphated zirconia. Appl Catal A: Gen 171:207

51. Mihályi RM, Lónyi F, Beyer HK, Szegedi Á, Kollár M, PálBorbély G, Valyon J (2013) n-Heptane hydroconversion over nickel-loaded aluminum- and/or boron-containing BEA zeolites prepared by recrystallization of magadiite varieties. J Mol Catal A: Chem 367:77-88

52. Tran M, Gnep N, Guisnet M, Nascimento P (1997) Influence of hydrogen and of reaction temperature on the mechanism of n-butane isomerization over sulfated zirconia. Catal Lett 47:57

53. Triwahyono S, Jalil AA, Ruslan NN, Setiabudi HD, Kamarudin $\mathrm{NHN}$ (2013) $\mathrm{C}_{5}-\mathrm{C}_{7}$ linear alkane hydroisomerization over $\mathrm{MoO}_{3}-\mathrm{ZrO}_{2}$ and $\mathrm{Pt} / \mathrm{MoO}_{3}-\mathrm{ZrO}_{2}$ catalysts. J Catal 303:50 
54. Weitkamp J, Jacobs PA, Martens JA (1983) Isomerization and hydrocracking of $\mathrm{C}_{9}$ through $\mathrm{C}_{16}$ n-alkanes on Pt/HZSM-5 zeolite. Appl Catal 8:123

55. Myers P, Watson K (1946) Principles of reactor design. Natl Pet News Tech SOC 38:388

56. Klein MT, Virk PS (1983) Model pathways in lignin thermolysis. 1. Phenethyl phenyl ether. Ind Eng Chem Fund 22:35

57. John TM, Wojciechowski BW (1975) On identifying the primary and secondary products of the catalytic cracking of neutral distillates. J Catal 37:240-250

58. Zhao YX, Bamwenda GR, Groten WA, Wojciechowski BW (1993) The chain mechanism in catalytic cracking: the kinetics of 2-Methylpentane cracking. J Catal 140:243

59. Best D, Wojciechowski BW (1977) On identifying the primary and secondary products of the catalytic cracking of cumene. J Catal 47:11

60. Bhore NA, Klein MT, Bischoff KB (1990) The delplot technique: a new method for reaction pathway analysis. Ind Eng Chem Res 29:313

61. Sie ST (1993) Acid-catalyzed cracking of paraffinic hydrocarbons. 3. Evidence for the protonated cyclopropane mechanism from hydrocracking/hydroisomerization experiments. Ind Eng Chem Res 32:403

62. Sie ST (1992) Acid-catalyzed cracking of paraffinic hydrocarbons. 1. Discussion of existing mechanisms and proposal of a new mechanism. Ind Eng Chem Res 31:1881
63. García-Gutiérrez JL, Cano JL, Alemán-Vázquez LO, JiménezCruz F (2012) Study of selectivity of $\mathrm{MoO}_{3}$-catalyzed $\mathrm{C}_{6}-\mathrm{C}_{7}$ hydrocarbons hydroisomerization: Mechanistic insights into the formation of carbonaceous deposits on the catalyst surface. Fuel 94:532

64. Busto M, Lovato ME, Vera CR, Shimizu K, Grau JM (2009) Silica supported tungsta-zirconia catalysts for hydroisomerization-cracking of long alkanes. Appl Catal A: Gen 355:123

65. Rosenberg DJ, Coloma F, Anderson JA (2002) Modification of the acid properties of silica-zirconia aerogels by in situ and ex situ sulfation. J Catal 210:218

66. Bensitel M, Saur O, Lavalley JC, Morrow BA (1988) An infrared study of sulfated zirconia. Mater Chem Phys 19:147

67. Valavarasu G, Sairam B (2013) Light naphtha isomerization process: a review. Petrol Sci Technol 31:580

68. Blomsma E, Martens J, Jacobs P (1996) Mechanisms of heptane isomerization on bifunctional $\mathrm{Pd} / \mathrm{H}$-Beta zeolites. J Catal 159:323

69. Blomsma E, Martens J, Jacobs P (1995) Reaction mechanisms of isomerization and cracking of heptane on $\mathrm{Pd} / \mathrm{H}-\mathrm{Beta}$ zeolite. J Catal 155:141

70. Guisnet M (2013) "Ideal" bifunctional catalysis over Pt-acid zeolites. Catal Today 218-219:123

71. Deldari H (2005) Suitable catalysts for hydroisomerization of long-chain normal paraffins. Appl Catal A: Gen 293:1 